biochemical aspects of energy metabolism. This is followed by a soction on energy metabolism of cows under different conditions, in which the papers are devoted to energy balance studies with various rations. Problems concerned with energy utilization during lactation received particular attention and provoked considerable interest and discussion.

Section 3 contains a number of useful reviews of up-to-date respiratory and calorimetric techniques. The application of computer processing techniques to energy balance invostigations should open up new possibilities for mass field trials and largo-scale experiments.

The evaluation of feeds as a source of energy has farrcaching applications in animal husbandry, and the section devoted to this topic is the longest in the book. It covers investigations on cattle, sheep and pigs, including such problems as the importance of urea in fibre utiliza tion, the effects of artificial drying or freezing of grass on its energy value, and studies on different energy sources for growing and fattening pigs. (The inclusion of a paper on the guinea-pig makes a refreshing change from the realms of agricultural economics.)

A small section is devoted to an assessment of the comparative slaughter technique for the determination of enorgy retention and net energy values of food. This technique would seem to be useful for chickons, but requires further justification for cows in view of their high cost.

The final major section is confined to investigations on onvironmental factors in metabolism and contains papers on the effects of wind and environmental temperature changes on metabolism and heat exchange in sheep and cattle, on general environmental factors in the young pig, and on the effect of barometric pressure changes on incubation in chickens.

The symposium ends with a discussion opened by Prof. Kleiber on the problem of metabolic body size, and this is followod by a report of the sub-committee on constants. General agreement was reached on the adoption of Prof. Kleiber's suggestion that $W^{3 / 4}$ be used as an index of metabolic size rather than the older formula of $W^{2 / 3}$ This diseussion and the report on the standardization and rationalization of factors used in estimating energy exchange from respiratory data will be valuable for all those engaged in this fiold.

The lack of a subject index in a book of this type detracts somewhat from its value. However, this was presumably sacrificed in order to avoid prolonged delay in publication and the decision is probably justified. The book should prove useful to those already engaged in problems of energy exchange in farm animals, but tho specialized nature of most of the papers means that it is unlikely to attract the general reader.

M. SILVER

\section{SCIENTISTS IN INDUSTRY}

\section{Professional Employees}

A Study of Scientists and Engineers. By Kenneth Prandy. (Society Today and Tomorrow.) Pp. 197. (London: Faber and Faber, Ltd., 1965.) 32s. 6d. net.

PROFESSIONAL Employees, a study of seientists and engineers in industrial society, is intended as a contribution to the theory of social stratification and as n contribution to the sociology of science. In the first introductory part the place and employment of technologists in industry aro discussed in relation to the latter aim and the relation betwoen class, status and professionalism in relation to the former. The second part of the book discusses professional associations generally but more especially the Institution of Metallurgists and tho Fngineers' Guild. In tho third part, trade unionism is considered generally, but again with special referenco to the Association of Scientific Workers. Even the study of that particular association is, however, too limited in scopo to give any wide validity to its findings, and generally the interest and value of the book derive not so much from the extent of any fresh studies or evidence, as from Mr. Prandy's own assessment of the material he has examined.

In scope, as well as in scale, his book is more limited than Carr-Saunders and Wilson's study of the professions a generation ago and, although some now material is covered, by and large the book adds little to that earlier authoritative appraisal. It is nearer to Lewis and Maude's Professional People, published in 1952, but more pedes. trian, although Mr. Prandy's comments are sometimes more penctrating. It resembles evon more nearly Kornhauser's Scientists in Industry, though that was concerned with the American scene and Mr. Prandy's study is limited to the United Kingdom. He also approaches J. Mills's The Engineer in Society, which Mr. Prandy appears to have missed and which, though more limited and again concerned with the United States, is commendably constructive and might have helped Mr. Prandy considerably. Nor does he appear to have noticed an earlier study from the International Labour Office of the status and employment of engineers and chemists in industry.

One weakness of the book is indeed on the biblio. graphical side. References are not as complete as they might be, nor are they always easy to locate. It is shaky also on the historical side, particularly in respect of chemists, for example. The Royal Institute of Chemistry has provided a professional qualification for considerably moro than half a century, and the Petersen judgment and some lively discussion on registration of professional bodies as trade unions in early publications, under the auspices of the British Association of Chemists, might have helped $\mathrm{Mr}$. Prandy considerably in his final assess. ment had he consulted them, as R. M. Wynne-Edwards's presidential address to the Institution of Civil Engineers in November 1964 might well also have done. The existence of the great engineers in the Victorian era is scarcely considered.

What has hindered Mr. Prandy from giving a more valuable and constructive book appears to be tho preconceived ideas with which he started. The concepts and aims which he acknowledges seem to have prevented the more searching and imaginative analysis that would have led to some real contribution to the urgent problem of the functions and place of the professional associations in socicty to-day (the study functions of which he is inclined to over-emphasize), to that of the status of the technician in relation to the technologist, or to the resolution of conflicting loyalties between profession, industry and society. Mr. Prandy is aware of all these issues and touches on them briefly, including that of the mechanism of advice on scientific policy, though he shows little awareness of the significance of the professional association. What enrichos the book, however, is his obvious capacity for penetrating thought and sound judgment, and his observations on many of the issues that arise, such as how to increase public appreciation of the importance of the technician, might have been suggestive and helpful, though incidentally he does not clearly distinguish between the technician and the technologist; he passes too lightly over the practical difficulty of attempting to meet tho needs of both in one organization, whether concerned with education and qualification or primarily with the defence of professional interests. He recognizes the primary difficulty of maintaining professional codes and standards when the professional worker is an employee, but the difficulty can be exaggernted and its importance could diminish. He recognizes also the significant differences in this respect between public and private employmont and, for all its limitations, the book brings together a good deal of information which could stimulate fruitful thinking about problems that concern the most efficient use of highly trained manpower. R. BRIGHTMaN 